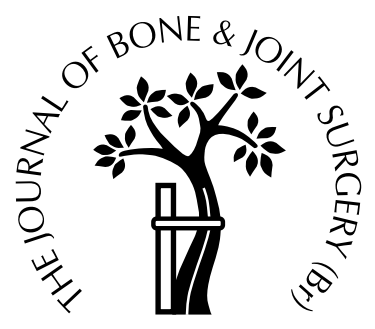

\title{
Small volume hypertonic hydroxyethyl starch reduces acute microvascular dysfunction after closed soft-tissue trauma
}

\author{
T. Mittlmeier, B. Vollmar, M. D. Menger, L. Schewior, M. Raschke, \\ K.-D. Schaser \\ From Humboldt University, Berlin, Germany
}

\begin{abstract}
A major pathway of closed soft-tissue injury is failure of microvascular perfusion combined with a persistently enhanced inflammatory response. We therefore tested the hypothesis that hypertonic hydroxyethyl starch (HS/HES) effectively restores microcirculation and reduces leukocyte adherence after closed soft-tissue injury. We induced closed soft-tissue injury in the hindlimbs of $\mathbf{1 4}$ male isofluraneanaesthetised rats. Seven traumatised animals received 7.5\% sodium chloride-6\% HS/HES and seven isovolaemic $0.9 \%$ saline (NS). Six non-injured animals did not receive any additional fluid and acted as a control group. The microcirculation of the extensor digitorum longus muscle (EDL) was quantitatively analysed two hours after trauma using intravital microscopy and laser Doppler flowmetry, i.e. erythrocyte flux. Oedema was assessed by the wet-todry-weight ratio of the EDL.

In NS-treated animals closed soft-tissue injury resulted in massive reduction of functional capillary density (FCD) and a marked increase in microvascular permeability and leukocyte-endothelial cell interaction as compared with the control group. By contrast, HS/HES was effective in restoring the FCD to $94 \%$ of values found in the control group. In addition, leukocyte rolling decreased almost to control levels and leukocyte adherence was found to be reduced by $\sim 50 \%$. Erythrocyte flux in NS-treated animals decreased to $90 \pm 8 \%$ (mean SEM), whereas values in the
\end{abstract}

T. Mittlmeier, MD

Trauma and Reconstructive Surgery, University of Rostock, Schillingallee 35, 18055 Rostock, Germany.

M. Raschke, MD

L. Schewior, MD

K.-D. Schaser, MD

Trauma and Reconstructive Surgery Charité, Humboldt University, Campus Virchow-Klinikum, Augustenburger Platz 1, D-13353 Berlin, Germany.

B. Vollmar, MD

M. D. Menger, MD

Institute for Clinical and Experimental Surgery, University of Saarland, Hamburg/Saar, Germany.

Correspondence should be sent to Dr K.-D. Schaser.

(C)2003 British Editorial Society of Bone and Joint Surgery doi:10.1302/0301-620X.85B1.11870 \$2.00
HS/HES group significantly increased to $137 \pm 3 \%$ compared with the baseline flux. Oedema in the HS/HES group $(1.06 \pm 0.02)$ was significantly decreased compared with the NS-group $(1.12 \pm 0.01)$.

HS/HES effectively restores nutritive perfusion, decreases leukocyte adherence, improves endothelial integrity and attenuates oedema, thereby restricting tissue damage evolving secondary to closed soft-tissue injury. It appears to be an effective intervention, supporting nutritional blood flow by reducing traumainduced microvascular dysfunction.

J Bone Joint Surg [Br] 2003;85-B:126-32.

Received 7 November 2000; Accepted after revision 26 February 2002

Clinically, there is emerging consensus that high levels of morbidity after complex injuries to the limbs are directly related to the severity of soft-tissue injury. ${ }^{1,2}$ Previous studies have shown that the propagation of closed soft-tissue injury is preceded by a drastic reduction of functional capillary density (FCD) and a marked increase in leukocyteendothelial-cell interaction as well as microvascular leakage. $^{2-4}$ Similar microcirculatory disturbances have been found to promote tissue damage in skeletal muscle in response to a variety of stimuli such as ischaemiareperfusion ${ }^{5,6}$ or infection. ${ }^{7}$ A major limitation, however, in the treatment of severe soft-tissue damage in trauma patients, is the general lack of effective tools for the rapid restoration of tissue perfusion and reduction of traumainduced inflammation. At present, the clinical management of severe soft-tissue trauma mainly relies on serial radical debridement of tissue which is necrotic or becomes necrotic during the clinical course. ${ }^{1}$

The ability of hypertonic-hyperoncotic solutions (i.e. exerting a higher than physiological plasma osmotic and oncotic pressure) to restore tissue perfusion and organ function efficiently and rapidly after haemorrhagic shock $^{8-10}$ and severe injury ${ }^{11-13}$ is now well recognised, but there is no information regarding their ability to improve efficiently the microcirculation of skeletal muscle after severe blunt trauma to the limbs. These observations have led to the hypothesis that hypertonic-hyperoncotic fluids may simultaneously exert a significant protective effect on post-traumatic microvascular haemodynamics, the leukocyte 
response, and the formation of oedema in skeletal muscle which, in turn, may positively influence tissue perfusion.

We have therefore determined quantitatively the acute effectiveness of treatment with hypertonic hydroxyethyl starch (HS/HES) on the microcirculation, the leukocyteendothelium interaction and the formation of oedema in skeletal muscle after severe closed soft-tissue trauma and compared this with treatment with normal saline (NS).

\section{Materials and Methods}

Animal model, impact device and surgical preparation. All experimental procedures were performed with the permission of the local animal rights protection authorities and in accordance with NIH guidelines for the use of laboratory animals. We induced severe standardised closed soft-tissue injury in the anterolateral tibial compartment of the left hindlimb of anaesthetised male Sprague-Dawley rats (isoflurane $1.5 \mathrm{vol} . \%, \mathrm{~N}_{2} \mathrm{O} 0.5 \mathrm{l} / \mathrm{min}$ and $\mathrm{O}_{2} 0.3 \mathrm{l} / \mathrm{min}$ ) using the computer-assisted controlled impact-injury technique. The controlled impact-injury device, which was originally developed for the induction of severe brain injury, ${ }^{14}$ employs a high-pressure pneumatic impactor which reproduces the clinical situation of severe closed soft-tissue injury caused by high-velocity trauma. The impact parameters were selected as follows: impact velocity of $7 \mathrm{~m} / \mathrm{s}$, deformation depth of $11 \mathrm{~mm}$ and impact duration of $100 \mathrm{~ms}$ with an impactor diameter of $11 \mathrm{~mm}$. The optimal absorption of impact energy by the soft tissue of the rat hindlimb was guaranteed by fixation of the limb in plastic form (exactly moulded like the hindlimb) tightly mounted to the table of the impact device. The left carotid artery and right jugular vein were cannulated with polyethylene catheters (PE50, $0.58 \mathrm{~mm}$ inner diameter; Portex, Hythe, UK) for continuous haemodynamic monitoring and intravenous administration of fluid and fluorescence markers. The extensor digitorum longus (EDL) of the left hindlimb was prepared for intravital fluorescence microscopy modified to the technique as previously described ${ }^{15}$ allowing horizontal positioning of the EDL and constant focus level for the microscopic procedure.

Experimental groups and protocol. We induced severe closed soft-tissue injury in 14 rats. Six non-traumatised, sham-operated animals served as a control group. The rats were allocated randomly to three treatments: trauma followed by hydroxyethyl starch (HS/HES); trauma followed by normal saline (NS); and controls with no trauma. Before the EDL was surgically exposed, the intramuscular pressure within the antero- and posterolateral tibial compartment ( 8 $\mathrm{mm}$ beneath the skin surface) was measured percutaneously (45 minutes after injury) using a microsensor catheter (0.7 mm outside diameter, Codman microsensor; Johnson \& Johnson Professional Inc, Raynham, Massachusetts).

After a period of stabilisation of 15 minutes, the macrohaemodynamics, arterial blood gases and blood chemistry were determined and laser Doppler flowmetry was per- formed. These procedures took place 1.5 hours after trauma before treatment. Seven traumatised animals were then infused intravenously over 15 minutes with $7.2 \%$ sodium chloride-10\% HS/HES ( $4 \mathrm{ml} / \mathrm{kg}$ body-weight; Hyperhaes, Fresenius $\mathrm{GmbH}$, Bad Homburg, Germany) $)^{10,11,16}$ and seven with the equivalent volume of $\mathrm{NS}(0.9 \% \mathrm{NaCl}$; Braun Melsungen AG, Melsungen, Germany). There was no significant difference in the administered volume per animal between the NS $(1.3 \pm 0.1 \mathrm{ml})$ and the HS/HES $(1.2 \pm 0.1$ $\mathrm{ml})$. The six non-injured, sham-operated rats in the control group received no additional fluid. The concentration of HS/ HES was $10 \%$ with a molecular weight of 200000 and a degree of substitution of 0.6 , i.e. the ratio of substituted (hydroxylated) glucose units to the total number of glucose molecules. ${ }^{17}$ HS/HES is a derivative of amylopectin and was chosen as the colloid component instead of dextran or albumin because of its enhanced ability to protect endothelial cells from inflammatory activation and subsequent dysfunction. ${ }^{17}$ Furthermore, dextran is known to induce severe anaphylaxis $^{18}$ and albumin may increase leakage from microvessels, adversely affecting haemostasis and possibly increasing mortality. ${ }^{19}$

After the period of infusion the macrohaemodynamics, arterial blood gases, and blood chemistry were again determined and laser Doppler flowmetry of all animals performed once more, two hours after injury, 30 minutes after treatment. The EDL was then sequentially scanned proximally to distally in $2 \mathrm{~mm}$ increments by intravital fluorescence microscopy to allow recording of microcirculatory images for nutritive capillaries and postcapillary venules. Microcirculatory recordings for nutritive capillaries and postcapillary venules of at least eight video-frames of each EDL muscle were taken and the values averaged per animal.

At the end of each experiment, the animals were killed and laser Doppler flowmetry of the non-perfused EDL muscle performed finally to assess the biological zero. ${ }^{20}$ Thereafter, the EDLs of both hindlimbs were removed for determination of the oedematous weight gain.

Intravital fluorescence microscopy. For visualisation of the microcirculation of the EDL we used an intravital fluorescence microscope (Optiphot; Nikon, Tokyo, Japan) with a water-immersion objective (203, Nikon). The surface of the EDL was epi-illuminated by a high-pressure mercury lamp $(100 \mathrm{~W})$ and fluorescence emission of fluorescein-isothiocyanate (FITC)-dextran (450 to $490 \mathrm{~nm} />580 \mathrm{~nm}$ ) and rhodamine (530 to $560 \mathrm{~nm} />580 \mathrm{~nm}$ ) was detected by means of an appropriate filter system. Microcirculatory images were recorded using a CCD videocamera (FK 6990IQ; Pieper, Schwete, Germany) and transferred to an SVHS videorecorder (HR-S4700EG/E; JVC, Friedberg, Germany) for off-line analysis. The final magnification on the video screen was 940-fold.

For contrast enhancement of the microvascular network and for in vivo staining of leukocytes a single bolus of FITC-labelled dextran $(5 \%, 150000 \mathrm{~mol} \mathrm{wt} ; 15 \mathrm{mg} / \mathrm{kg}$ body-weight; Sigma Chemical, Deisenhofen, Germany) and 
Table I. Mean ( \pm SEM) arterial blood pressure $(\mathrm{mmHg})$ and heart rate (beats/min) of isoflurane anaesthetised animals, continuously recorded and averaged for the entire study period

\begin{tabular}{lcl}
\hline Group & $\begin{array}{l}\text { Mean arterial } \\
\text { blood pressure }\end{array}$ & Heart rate \\
\hline Control & $107 \pm 5$ & $254 \pm 10$ \\
NS & $90 \pm 4$ & $304 \pm 10$ \\
HS/HES & $95 \pm 2$ & $299 \pm 18$ \\
\hline
\end{tabular}

rhodamine $6 \mathrm{G}(0.1 \%, 0.15 \mathrm{mg} / \mathrm{kg}$ body-weight; Sigma Chemical) was injected intravenously. ${ }^{21}$ Duration of continuous light exposure per observation area was limited to 60 seconds at maximum.

Microcirculatory analysis. The videotaped microcirculatory images were analysed off-line for the diameters of microvessels, FCD, microvascular permeability (macromolecular leakage) and red blood cell velocity $\left(\mathrm{V}_{\mathrm{RBC}}\right)$ using a computerised microcirculation image-analysis system (CapImage; Zeintl, Heidelberg, Germany). ${ }^{22}$ FCD was quantified by the length of FITC-dextran-perfused capillaries per observation area $\left(\mathrm{cm}^{-1}\right)$. Microvascular permeability (macromolecular leakage) was expressed as the ratio of fluorescence-intensity, selected from the perivascular area to the corresponding intravascular area (plasma gaps between erythrocytes).

Using the PC-associated image-analysis system we determined centreline red blood cell velocity $\left(\mathrm{V}_{\mathrm{RBC}}\right.$-centreline) in the capillaries and venules of skeletal muscle. ${ }^{22}$ The mean red blood cell velocity for each vessel $\left(V_{R B C}\right.$ mean) and video field was calculated as $V_{\text {mean }}=V_{\text {centreline }} /$ 1.6. Venular wall shear rate as a function of the disperse force on rolling leukocytes was calculated as follows: shear rate $=8 \times \mathrm{V}_{\text {mean }} / \mathrm{D}$, where $\mathrm{V}_{\text {mean }}$ is mean erythrocyte velocity and $\mathrm{D}$ is venular diameter. ${ }^{23}$

The number of rolling and adherent leukocytes as well as the total leukocyte flux were counted for 30 seconds along a vessel segment of $100 \mathrm{~mm}$. Leukocyte rolling was defined as the slow passage of leukocytes rolling along the vessel wall with a velocity less than $40 \%$ of centreline velocity 24 and expressed as the percentage of rolling cells to total leukocyte flux. Adherence of leukocytes was defined by nonmoving leukocytes with a stable contact to the endothelial lining of postcapillary venules for at least 20 seconds. Assuming cylindrical microvessel geometry, leukocyte adherence was expressed as the number of non-moving leukocytes per endothelial surface $\left(\right.$ cells $/ \mathrm{mm}^{2}$ ), calculated from the diameter and length $(100 \mathrm{~mm})$ of the vessel segment analysed.

Laser Doppler flowmetry. Erythrocyte flux was measured using a dual-channel laser Doppler monitor (DRT4; Moore Instruments, Axminster, UK; needle probe DP4, 780-820 $\mathrm{nm}$, external diameter $0.8 \mathrm{~mm}$ ) and expressed as percentage of baseline (pretreatment flux values). By means of a threedimensional micromanipulator, the EDL was sequentially scanned in increments of $1 \mathrm{~mm}$ reaching at least 20 measurements per EDL.
Table II. Time-related changes in arterial haematocrit (\%), acid-base excess (BE), arterial $\mathrm{pH}$, serum sodium, potassium and chloride concentrations (nmol/l), creatine kinase $(\mathrm{CK})$ and arterial lactate at baseline, in response to trauma and at 30 minutes after treatment. Values are expressed as mean \pm SEM

\begin{tabular}{|c|c|c|c|}
\hline Group & Baseline & $\begin{array}{l}1.5 \text { hours } \\
\text { after trauma } \\
\text { (before } \\
\text { treatment) }\end{array}$ & $\begin{array}{l}2 \text { hours } \\
\text { after trauma } \\
(30 \text { minutes } \\
\text { after } \\
\text { treatment })\end{array}$ \\
\hline \multicolumn{4}{|c|}{ Haematrocrit (\%) } \\
\hline Control & $41.1 \pm 1.2$ & - & - \\
\hline NS & $39.5 \pm 1.6$ & $37.9 \pm 1.2$ & $35.3 \pm 1.4$ \\
\hline HS/HES & $41.1 \pm 1.2$ & $39.6 \pm 1.0$ & $28.9 \pm 1.4^{*}+\ddagger$ \\
\hline \multicolumn{4}{|c|}{$\mathrm{BE}(\mathrm{mmol} / \mathrm{l})$} \\
\hline Control & $2.8 \pm 0.7$ & & \\
\hline $\mathrm{NS}$ & $4.4 \pm 0.8$ & $0.03 \pm 0.7$ & $-1.0 \pm 1.5^{*}$ \\
\hline HS/HES & $2.0 \pm 0.8$ & $0.3 \pm 1.4$ & $-1.6 \pm 0.9 *$ \\
\hline \multicolumn{4}{|l|}{$\mathrm{pH}$} \\
\hline Control & $7.43 \pm 0.02$ & - & - \\
\hline NS & $7.44 \pm 0.01$ & $7.38 \pm 0.02$ & $7.36 \pm 0.04$ \\
\hline HS/HES & $7.43 \pm 0.02$ & $7.39 \pm 0.03$ & $7.35 \pm 0.02 *$ \\
\hline \multicolumn{4}{|c|}{ Serum $\mathrm{Na}^{+}(\mathrm{nmol} / \mathrm{l})$} \\
\hline Control & $140.5 \pm 1.5$ & - & \\
\hline NS & $139.8 \pm 0.5$ & $137.7 \pm 1.1$ & $139.7 \pm 1.0$ \\
\hline HS/HES & $138.7 \pm 1.1$ & $136.7 \pm 0.4$ & $146.9 \pm 0.69 * \dagger \dagger$ \\
\hline \multicolumn{4}{|c|}{ Serum K ${ }^{+}(\mathrm{nmol} / \mathrm{l})$} \\
\hline Control & $4.1 \pm 0.7$ & - & - \\
\hline NS & $4.1 \pm 0.2$ & $4.8 \pm 0.2$ & $4.5 \pm 0.2$ \\
\hline HS/HES & $4.5 \pm 0.2$ & $4.8 \pm 0.3$ & $4.3 \pm 0.3$ \\
\hline \multicolumn{4}{|c|}{ Serum $\mathrm{Cl}^{-}(\mathrm{nmol} / \mathrm{l})$} \\
\hline Control & $102.7 \pm 0.6$ & - & - \\
\hline $\mathrm{NS}$ & $103.8 \pm 0.5$ & $102.7 \pm 0.7$ & $107.2 \pm 1.2$ \\
\hline HS/HES & $102.9 \pm 0.9$ & $103.3 \pm 0.4$ & $119.0 \pm 0.6^{*} \dagger t$ \\
\hline \multicolumn{4}{|l|}{ CK (U/L) } \\
\hline Control & $67.6 \pm 5.7$ & - & - \\
\hline NS & $90.3 \pm 11.8$ & $188.3 \pm 15.8^{*}$ & $174.6 \pm 28.5^{*}$ \\
\hline HS/HES & $80.5 \pm 9.2$ & $245.0 \pm 37.8^{*}$ & $238.7 \pm 54.9^{*}$ \\
\hline \multicolumn{4}{|c|}{ Lactate $(\mathrm{mg} / \mathrm{dl})$} \\
\hline Control & $19.5 \pm 2.1$ & - & - \\
\hline NS & $16.3 \pm 0.7$ & $14.0 \pm 1.8$ & $12.2 \pm 1.9$ \\
\hline HS/HES & $20.3 \pm 2.3$ & $19.9 \pm 1.7$ & $17.1 \pm 3.2$ \\
\hline
\end{tabular}

$* \mathrm{p}<0.01$ versus baseline

$\dagger \mathrm{p}<0.01$ versus 1.5 hours after trauma

$\pm \mathrm{p}<0.05$ versus $\mathrm{NS}$

Blood sampling. Arterial blood samples were taken before (baseline) and at 1.5 hours and at two hours after injury, 30 minutes after administration of either HS/HES or NS. Arterial blood gases were assessed using a blood-gas analyser (ABL 300; Radiometer, Copenhagen, Denmark). Plasma electrolyte concentrations were measured using a potentiometric test. Based on enzymatic ultraviolet methods the levels of plasma lactate were obtained by a colorimetric test $(540 \mathrm{~nm})$ whereas the activity of creatine kinase (CK) was determined by a multiple-point kinematic test $(670 \mathrm{~nm})$ (Vitros products chemistry; Eastman Kodak Company, Rochester, New York).

Determination of the formation of skeletal muscle oedema. Oedematous weight gain was assessed by measuring the wet-to-dry-weight ratio of injured and non-injured EDLs. After determination of wet weight the EDLs were dried for 24 hours in a laboratory oven $\left(80^{\circ} \mathrm{C}\right)$ and weighed again (dry weight). Stable dry weight was found after 24 
Table III. Intramuscular pressure percutaneously measured in $\mathrm{mm}$ $\mathrm{Hg} 45$ minutes after trauma in the ventral and dorsal tibial compartment of rat hindlimbs and oedematous weight gain of the EDL as expressed by the oedema index (wet-to-dry-ratio of experimental versus contralateral EDL)

\begin{tabular}{lccl}
\hline & \multicolumn{2}{l}{ Intramuscular pressure } & \\
\cline { 2 - 3 } Group & Ventral & Dorsal & Oedema index \\
\hline Control & $6.3 \pm 0.4$ & $5.1 \pm 0.6$ & $1.01 \pm 0.03$ \\
NS & $21.5 \pm 0.8^{*}$ & $11.7 \pm 0.6$ & $1.11 \pm 0.01^{*}$ \\
HS/HES & $20.7 \pm 0.4^{*}$ & $9.1 \pm 0.6^{*}$ & $1.06 \pm 0.02 \dagger$ \\
\hline
\end{tabular}

$* \mathrm{p}<0.05$ versus control

$\dagger \mathrm{p}<0.05$ versus $\mathrm{NS}$

hours in all animals. The formation of oedema was finally expressed by the wet-to-dry-weight ratio of injured versus non-injured EDL (oedema index).

Statistical analysis. All time points within a group were analysed by a paired $t$-test, including Bonferroni correction for repeated measurements which involved dividing the threshold $\mathrm{p}$ value by 3 ( $\mathrm{k}=3$ as the number of pairwise comparisons performed between the three repeated measures on the same rat). For differences between NS, HS/HES and control groups we performed ANOVA for independent samples followed by the post-hoc Tukey-test for multiplecomparison procedures. Erythrocyte flux between the HS/ HES and NS groups was compared using the unpaired $t$-test. All values were given as mean \pm SEM. Statistical significance was set at $\mathrm{p}<0.05$.

Results

Macrohaemodynamics and blood parameters. The mean arterial blood pressure and heart rate of the experimental groups remained stable within the normal range without significant changes between groups throughout the entire study period when compared with the non-injured animals (Table I). Before treatment there were no significant differences between the two experimental groups as to blood gases and blood chemistry. In both experimental groups trauma led to a significant increase in the levels of creatine kinase and a slight development of metabolic acidosis (Table II). Treatment with HS/HES, however, was associated with a significant decrease in haematocrit and $\mathrm{pH}$ when compared with administration of NS. Simultaneously, haemodilution with HS/HES was paralleled by a significant increase in the concentration of serum sodium and chloride when compared with NS-treated animals (Table II).

Intramuscular pressure. As early as one hour after the induction of closed soft-tissue injury intramuscular pressure within the anterior and posterior tibial compartment was significantly increased in groups receiving NS or HS/HES when compared with the control group. However, at no time point of analysis did the closed soft-tissue injury result in intramuscular pressure exceeding $30 \mathrm{~mm} \mathrm{Hg}$ indicating a compartment syndrome (Table III).

Post-traumatic skeletal muscle microcirculation and small volume infusion of HS/HES. The post-traumatic
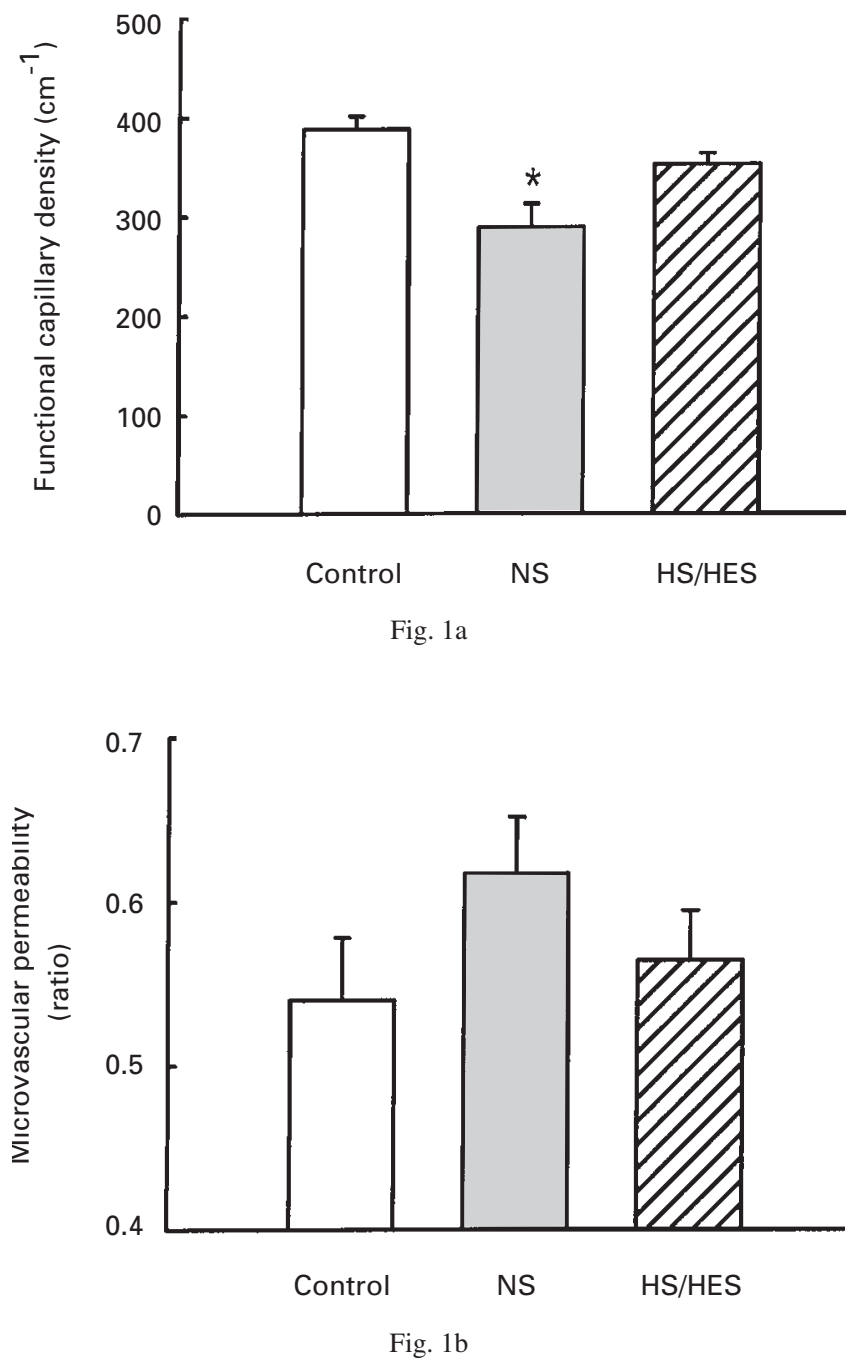

Graphs showing a) mean ( \pm SEM) FCD (length of erythrocyte perfused capillaries per observation area) and b) mean ( \pm SEM) microvascular permeability (venular macromolecular leakage of FITC-dextran) analysed densitometrically by the ratio of extra- to intravascular fluorescence intensity in rat skeletal muscle under control conditions and at two hours after trauma, i.e. 30 minutes after treatment with either NS or HS/HES ( $p<0.05 v$ control).

microcirculation in skeletal muscle in NS-treated animals was characterised by a significant reduction in the FCD and a trend towards enhanced microvascular permeability as compared with the control group (Fig. 1). In the NS-treated group, impairment of nutritive perfusion was further accompanied by a marked increase in trauma-induced leukocyteendothelial cell interaction compared with the control group. Both leukocyte rolling and adherence were primarily restricted to the endothelium of postcapillary venules and increased by nearly two- and sixfold (Fig. 2). These microvascular deteriorations were significantly improved when animals were treated with HS/HES. As early as 30 minutes after administration of HS/HES the FCD was restored to $94.7 \%$ of values found in the sham-operated control group (Fig. 1). Analysis of microvessel diameter revealed a signif- 


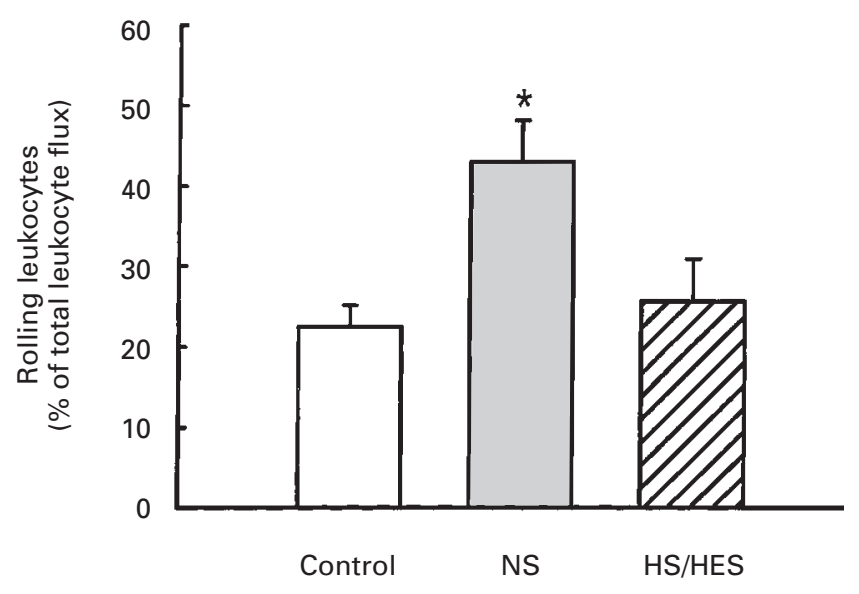

Fig. 2a

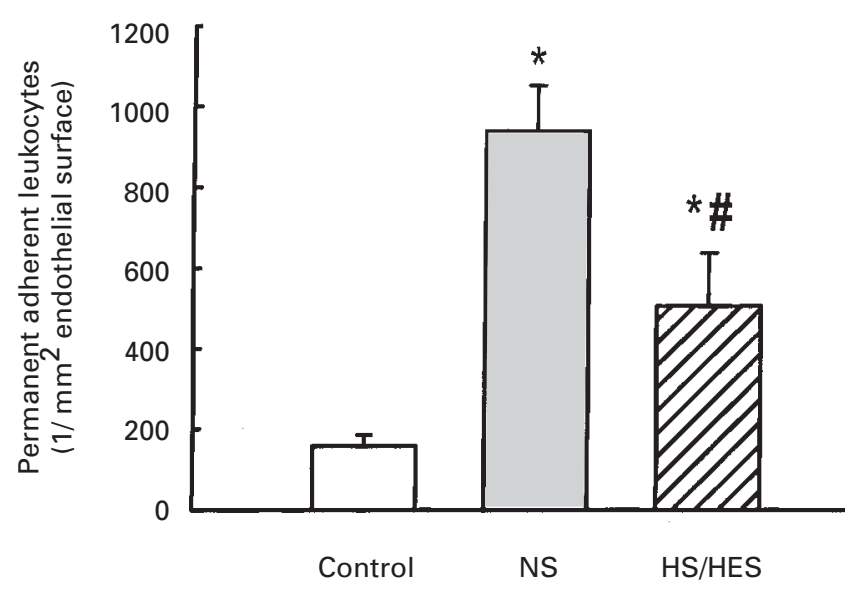

Fig. 2b

Leukocyte-endothelial cell interaction in postcapillary venules of rat EDL under control conditions (non-injured animals) and after treatment with either NS or HS/HES at two hours after injury. Leukocytes were stained in vivo by rhodamine $6 \mathrm{G}$. Figure $2 \mathrm{a}-$ Mean $( \pm$ SEM) number of rolling leukocytes and b) mean $\left( \pm\right.$ SEM) number of adherent leukocytes per $\mathrm{mm}^{2}$ endothelial surface $\left(\mathrm{p}^{*}<0.05 v\right.$ control, $\left.\mathrm{p} \#<0.05 v \mathrm{NS}\right)$.

icant increase in capillary diameter in the EDL of NStreated animals when compared with the control group whereas in animals of the HS/HES group, the lumenal diameter of the capillaries remained relatively unchanged (Table IV). Red blood cell velocity in both nutritive capillaries and postcapillary venules did not change significantly on treatment with HS/HES when compared with NS. Traumainduced leukocyte rolling in HS/HES-treated animals decreased almost to the baseline levels of the non-traumatised control group, and leukocyte adherence was significantly attenuated by approximately $50 \%$ compared with the NS group (Fig. 2). Venular shear rate showed no significant difference between both groups (Table IV).

Laser Doppler flowmetry. Post-traumatic erythrocyte flux in the EDL of animals receiving HS/HES showed a signifi-
Table IV. Mean ( \pm SEM) lumenal diameter and mean ( \pm SEM) red blood cell velocity in capillaries and venules as well as calculated postcapillary wall shear rate in rat skeletal muscle after severe closed soft-tissue trauma

\begin{tabular}{|c|c|c|c|c|c|}
\hline \multirow[b]{2}{*}{ Group } & \multicolumn{2}{|c|}{ Diameter $(\mu \mathrm{m})$} & \multicolumn{2}{|c|}{$\begin{array}{l}\text { Red blood cell velocity } \\
(\mathrm{mm} / \mathrm{sec})\end{array}$} & \multirow{2}{*}{$\begin{array}{l}\text { Shear rate } \\
\text { (1/sec) } \\
\text { (venules) }\end{array}$} \\
\hline & Capillaries & Venules & Capillaries & Venules & \\
\hline Control & $5.0 \pm 0.1$ & $22.3 \pm 1.9$ & $0.20 \pm 0.01$ & $0.23 \pm 0.03$ & $88.1 \pm 13.8$ \\
\hline NS & $5.4 \pm 0.2 *$ & $24.1 \pm 1.4$ & $0.17 \pm 0.04$ & $0.25 \pm 0.03$ & $117.0 \pm 13.3$ \\
\hline HS/HES & $5.1 \pm 0.4$ & $20.5 \pm 1.3$ & $0.15 \pm 0.01$ & $0.28 \pm 0.04$ & $94.3 \pm 13.5$ \\
\hline
\end{tabular}

cant increase by one-third of preinfusion flux values, whereas flux values after treatment with NS declined below the baseline level (preinfusion flux values) (Fig. 3).

Formation of oedema. In the non-injured, sham-operated control group, negligible oedema within skeletal muscle was found two hours after trauma. The NS-treated traumatised animals, however, showed a significant increase in the oedema index. By contrast, formation of oedema in the HS/ HES-treated group was significantly decreased (Table III).

\section{Discussion}

Intramuscular pressure. The fact that closed soft-tissue injury was equally pronounced in both groups points to a standardised induction of closed soft-tissue injury by the controlled impact-injury technique as a precondition for comparing effects of different treatments.

Systemic haemodynamics and blood parameters. Contrary to previous studies of traumatic haemorrhagic shock and hypotension in which hypertonic-hyperosmotic solutions were shown rapidly and efficiently to restore severely depressed macrohaemodynamics, ${ }^{8,12,13,25}$ in our study the mean arterial blood pressure and heart rate were not affected by infusion of HS/HES. Normovolaemic conditions and the missing systemic fluid imbalance between the intra- and extracellular space have already been discussed as possible factors accounting for the lack of macrohaemodynamic changes. $^{25,26}$

The significant decrease in haematocrit in HS/HEStreated animals presumably reflects the ability of HS/HES to initiate a rapid shift of fluid from the intracellular to the extracellular-intravascular compartment, ${ }^{9}$ thereby causing marked haemodilution and improvement of blood fluidity. Furthermore, apart from reduction in endothelial cell swelling this osmotic gradient also seems to draw fluid from the erythrocytes. This possibly decreases red blood cell volume, reduces hydraulic flow pressure and may in part contribute to rheological improvement in microvascular perfusion and faster washout of toxic metabolites including free radicals and proinflammatory cytokines. The apparently negative side-effect of a significantly decreased $\mathrm{pH}$ in the HS/HES group is thought to be related to a hyperchloraemic metabolic acidosis ${ }^{16}$ since lactate levels and arterial blood gases were within the normal range and did not differ between groups. 


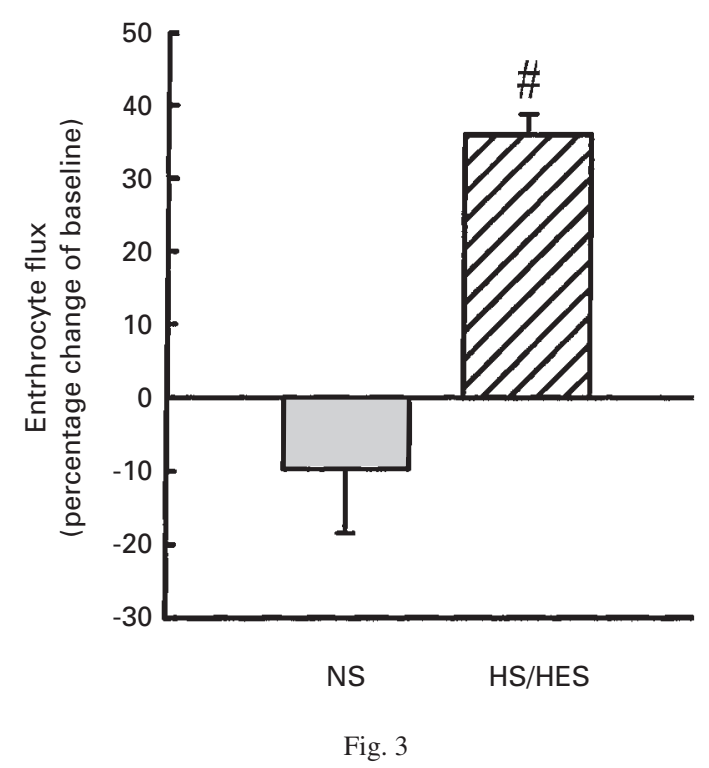

Mean ( \pm SEM) change in blood flow (erythrocyte flux measured by laser Dop. pler flowmetry) of rat EDL two hours after trauma and 30 minutes after treatment with either HS/HES or NS (p\#<0.05 $v$ NS).

The observation that hypertonic-hyperosmotic infusions are detrimental under some circumstances,${ }^{27}$ yet protective in others ${ }^{8,12,13,25}$ indicates potential risks of treatment with such fluids. These are specifically relevant in critically injured, dehydrated and high-risk patients ${ }^{28}$ and seem to be related to an increased plasma osmolarity and hypokalaemia causing cardiac arrhythmia and a metabolic acidosis induced by an increased plasma chloride anion load, thereby augmenting pre-existing acidosis. ${ }^{16}$ In severely injured patients, however, there is now increasing consensus that selective and only primary application of these fluids appears to have a good risk-to-benefit ratio and gives better patient survival ${ }^{12,18}$ when tailored to the underlying circulatory state. ${ }^{10,16}$

Post-traumatic skeletal muscle microcirculation. The observation that microvascular disturbances of skeletal muscle may be considered to be a starting point for developing tissue damage after severe standardised closed softtissue injury confirms previous studies. ${ }^{3,4}$ They are likely to be the consequence of several factors, including direct destruction of microvessels, microvascular thrombosis and decreased nutritive capillary perfusion, persistently enhanced leakage and leukocyte-endothelial cell interaction leading to increased oedema and tissue pressure. Together, these factors appear progressively to impede the viability and function of the entire skeletal muscle.

In our study we have shown that HS/HES acutely ameliorates the post-traumatic microcirculation by increasing the FCD and endothelial integrity. These beneficial effects on nutritional blood flow possibly illustrate the essential principle of small volume resuscitation which is thought to function primarily by an osmotically-induced fluid shift into the intravascular compartment. ${ }^{9,10}$ On the microcirculatory level this could attenuate tissue oedema, reduce intercapillary distance and tissue pressure, and enhance blood fluidity because of a decreased hydraulic flow resistance. From this it may be argued that HS/HES exerts its beneficial effects in closed soft-tissue injury by maintaining adequate perfusion or even reopening capillaries which otherwise would remain collapsed. In studies showing reversal of shock- or ischaemia-induced capillary narrowing by hypertonic-hyperoncotic solutions this has been interpreted as direct evidence of the ability of HS/HES to reduce swelling of endothelial cells. ${ }^{9,29}$ In our study, however, lumenal capillary diameters were found to be unchanged in response to HS/HES. This suggests that the cellular basis of the HS/HES-mediated protection of the post-traumatic microcirculation differs partly from the HS/HES-induced mechanisms responsible for reversal of shock- ${ }^{8,9}$ or ischaemia-induced capillary dysfunction. ${ }^{26,29}$

Previous studies have shown that although endothelial integrity is deranged immediately after closed soft-tissue injury, microvascular permeability displays a gradual increase with significant peak levels not earlier than 24 hours after injury. ${ }^{3,4}$ Thus, it is conceivable that two hours after closed soft-tissue injury, i.e. one hour of treatment with HS/HES, macromolecular leakage is just about to increase and initial changes are too small to reveal a significant difference.

Treatment of severe closed soft-tissue injury with HS/ HES did not significantly affect capillary and venular red blood cell velocity. These findings are in line with previous studies. Using hyperosmolar saline dextran for the treatment of reperfusion injury in striated muscle of hamsters, Nolte et $\mathrm{al}^{26}$ also found no effect on blood flow velocity when compared with normal saline.

In addition, HS/HES was also shown significantly to reduce the accumulation and adherence of leukocytes to the endothelium of postcapillary venules, which have been shown to be critically involved in the generation of postischaemic ${ }^{6,30,31}$ and post-traumatic microvascular injury. ${ }^{4}$ These leukocyte-mediated pathways, including production of reactive $\mathrm{O}_{2}$ radicals, expression of adhesion molecules, and increase in hydraulic flow pressure because of microvascular adherence ${ }^{30}$ are promoting a persistent proinflammatory state with subsequent tissue damage. Although HS/HES induced significant haemodilution (haematocrit $28 \% v 35 \%$ ) red blood cell velocity was only slightly shifted to higher values and calculated venular wall shear rates were comparable between both experimental groups. Therefore it is likely that the difference in the number of rolling and adherent leukocytes did not solely result from changes in physical forces or rheological characteristics, counteracting leukocyte-endothelial cell contact. Direct evidence for this selective inhibitory effect of HS/ HES on leukocyte-endothelial cell interaction in traumatised skeletal muscle has not been provided so far. Specifically, the lower microvascular haematocrit associated with a decreased margination of leukocytes within the bloodstream 
causing less endothelial contact appears to be one principal cause for reduced leukocyte adherence after treatment with HS/HES. ${ }^{29,32}$

Erythrocyte flux as assessed by laser Doppler flowmetry is calculated from the product of velocity and concentration of moving blood cells. ${ }^{20}$ Red blood cell velocity in capillaries and postcapillary venules remained unchanged in response to HS/HES when compared with NS (Table IV). Therefore, the significant HS/HES-induced increase in erythrocyte flux possibly reflects the enhanced total blood cell movement (concentration) caused by the increase in length and number of perfused capillaries, i.e. the FCD.

However, the results should be interpreted with reference to the fact that only acute effects of HS/HES on the microcirculation were analysed. Further investigations are required to analyse whether the initial boosting effects of HS/HES on the post-traumatic microcirculation are only transient in nature or will indeed last and significantly improve the net biological response over time.

In conclusion, our findings provide evidence that acute microvascular deteriorations, trauma-induced inflammatory response and tissue oedema after closed soft-tissue injury may be effectively reversed by small volume infusion of HS/HES. They reinforce the concept that the post-traumatic microcirculation may serve as a target for therapeutic interventions. Therefore, the appropriate use of HS/HES after severe closed soft-tissue injury appears to be an effective primary intervention which may support tissue perfusion and protect soft tissue from regional shock phenomena by prevention of microvascular dysfunction.

This work was supported by grants from the AO-ASIF Foundation, Switzerland and the Else-Kröner-Fresenius Foundation, Germany. B. Vollmar is a recipient of the Heisenberg-Stipendium of the Deutsche Forschungsgesellschaft (Vo 450/6-1).

No benefits in any form have been received or will be received from a commercial party related directly or indirectly to the subject of this article.

\section{References}

1. Levin LS, Condit DP. Combined injuries - soft tissue management. Clin Orthop 1996;327:172-81.

2. Tscherne H, Oestern HJ. A new classification of soft-tissue damage in open and closed fractures. Unfallheikunde 1982;85:111-5.

3. Mittlmeier T, Schaser K, Kroppenstedt S, et al. Microvascular response to closed soft tissue injury. Trans Orthop Res Soc 1997;44:317.

4. Schaser K, Vollmar B, Menger MD, et al. In vivo analysis of microcirculation following closed soft tissue injury. J Orthop Res 1999; 17:678-85.

5. Allen DM, Chen LE, Seaber AV, Urbaniak JR. Pathophysiology and related studies of the no reflow phenomenon in skeletal muscle. Clin Orthop 1995;314:122-33.

6. Menger MD, Pelikan S, Steiner D, Messmer K. Microvascular ischemia-reperfusion injury in striated muscle: significance of "reflow paradox". Am J Physiol 1992;263:H1901-6.

7. Lam C , Tym IK, Martin C, Sibbald W. Microvascular perfusion is impaired in a rat model of normotensive sepsis. J Clin Invest 1994;94:2077-83.

8. Vollmar B, Lang G, Menger MD, Messmer K. Hypertonic hydroxyethyl starch restores hepatic microvascular perfusion in hemorrhagic shock. Am J Physiol 1994;266:H1927-34.
9. Mazzoni MC, Borgstrom P, Intaglietta M, Arfors KE. Capillary narrowing in hemorrhagic shock is rectified by hyperosmotic saline-dextran reinfusion. Circ Shock 1990;31:407-18.

10. Kreimeier U, Christ F, Frey L, et al. Small-volume resuscitation for hypovolemic shock: concept, experimental and clinical results. Anaesthesist 1997;46:309-28.

11. Holcroft JW, Vassar MJ, Perry CA, Gannaway WL, Kramer GC. Use of a $7.5 \% \mathrm{NaCl} / 6 \%$ Dextran 70 solution in the resuscitation of injured patients in the emergency room. Prog Clin Biol Res 1989;299:331-8.

12. Mattox KL, Maningas PA, Moore EE, et al. Prohospital hypertonic saline/dextran infusion for post-traumatic hypotension: the U.S.A. multicenter trial. Ann Surg 1991;213:482-91.

13. Vassar MJ, Fischer RP, O'Brien PE, et al. A multicenter trial for resuscitation of injured patients with $7.5 \%$ sodium chloride: the effect of added dextran 70 . The multicenter group for the study of hypertonic saline in trauma patients. Arch Surg 1993;128:1003-11.

14. Dixon CE, Clifton GL, Lighthall JW, Yaghmai AA, Hayes RL. A controlled cortical impact model of traumatic brain injury in the rat. $J$ Neurosci Methods 1991;39:253-62.

15. Tyml K, Budreau CH. A new preparation of rate extensor digitorum longus muscle for intravital investigation of the microcirculation. Int $J$ Microcir Clin Exp 1991;10:335-43.

16. Vassar MJ, Perry CA, Holcroft JW. Analysis of potential risks associated with $7.5 \%$ sodium chloride resuscitation of traumatic shock. Arch Surg 1990;125:1309-15.

17. Treib J, Baron JF, Grauer MT, Strauss RG. An international view of hydroxyethyl starches. Intensive Care Med 1999;25:258-68.

18. Allhoff T, Lenhart FP. Severe dextran-induced anaphylactic/anaphylactoid reaction despite preventive hapten administration. Infusionsther Transfusionsmed 1993;20:301-6.

19. Reviewers. CIGA. Human albumin administration in critically ill patients: systematic review of randomised controlled trials. $B M J$ 1998;317:235-40.

20. Bonner R, Nossal R. Model of Laser-Doppler measurements of blood flow in tissue. Appl Optics 1981;20:2097-2107.

21. Menger MD, Lehr HA. Scope and perspectives of intravital microscopy - bridge over form in vitro to in vivo. Immunol Today 1993;14:519-22.

22. Klyscz T, Junger M, Jung F, Zeintl H. Cap image - a new kind of computer-assisted video image analysis system for dynamic capillary microscopy. Biomed Tech (Berl) 1997;42:168-75.

23. Bienvenu K, Granger N. Molecular determinants of shear rate-dependent leukocyte adhesion in postcapillary venules. Am J Physiol 1993;264:H1504-8.

24. Atherton A, Born GV. Quantitative investigations of the adhesiveness of circulating polymorphonuclear leukocytes to blood vessel walls. $J$ Physiol 1972;222:447-74.

25. Velasco IT, Rocha e Silva M, Oliveira MA, Oliveira MA, Silva RI. Hypertonic and hyperoncotic resuscitation from severe hemorrhagic shock in dogs: a comparative study. Crit Care Med 1989;17:261-4.

26. Nolte D, Bayer M, Lehr HA, et al. Attenuation of postischemic microvascular disturbances in striated muscle by hyperosmolar saline dextran Am J Physiol 1992;263:H1411-6.

27. Bickell WH, Bruttig SP, Millnamow GA, O'Benar J, Wade CE. Use of hypertonic saline/dextran versus lactated Ringer's solution as a resuscitation fluid after uncontrolled aortic hemorrhage in anesthetized swine. Ann Emerg Med 1992;21:1077-85.

28. Holcroft JW, Vassar MJ, Turner JE, Derlet RW, Kramer GC. 3\% $\mathrm{NaCl}$ and $7.5 \% \mathrm{NaCl} /$ dextran 70 in the resuscitation of severely injured patients. Ann Surg 1987;206:279-88.

29. Menger MD, Thierjung C, Hammersen F, Messmer K. Dextran vs hydroxyethylstarch in inhibition of postischemic leukocyte adherence in striated muscle. Circ Shock 1993;41:248-55.

30. Rubin BB, Romaschin A, Walker PM, Gute DC, Korthuis RJ. Mechanism of postischemic injury in skeletal muscle: intervention strategies J Appl Physiol 1996;80:369-87.

31. Weiss SJ. Tissue destruction by neutrophils. $N$ Engl J Med 1989;320:365-76.

32. Bagge U, Blixt A, Strid KG. The initiation of post-capillary margination of leukocytes: studies in vitro on the influence of erythrocyte concentration and flow velocity. Int J Microcirc Clin Exp 1983;2:21527. 